\title{
Sexual Assault on College Campuses: Substance Use, Victim Status Awareness, and Barriers to Reporting
}

\author{
Jill Schwarz, PhD, NCC \\ Sandy Gibson, PhD, LCSW \\ Carolynne Lewis-Arévalo, MA \\ The College of New Jersey
}

\begin{abstract}
Background: Despite the high incidence of estimated sexual assault on college campuses, underreporting is substantial and perpetuated by a culture of rape myths that are pervasive across college campuses and society in general.

Aim: The aim of this study was to: examine college student awareness of their own sexual assault victimization status, barriers to reporting, and the prevalence of substance use in sexual assault.

Method: This was a cross-sectional mixed-method survey sent to a universal sample of college students from two neighboring institutions of higher education $(\mathrm{N}=2,724)$.

Results: Results from this survey demonstrated a lack of understanding of what constitutes sexual assault, primarily attributed to the normalization of assault and rape myths. Regardless of victim status awareness, those who were victimized were significantly more likely to use higher levels of alcohol than non-victims, and were less likely to identify their victimization as sexual assault, highlighting the need for college students to understand that alcohol-involved sexual assault is still sexual assault.

Conclusions: Overwhelmingly, participants cited the potential consequences as far greater than any potential benefits to reporting sexual assault. Confusion about what constitutes sexual assault and uncertainty of available resources were also recognized as contributing factors in underreporting.
\end{abstract}

Submitted 5 December 2016: Accepted 20 July 2017

Keywords: Sexual assault, reporting, victim awareness, alcohol, rape culture

Incidences of sexual assault on college campuses are high, with an estimated one-in-four women being sexually victimized during their college years (Hines, Armstrong, Reed, \& Cameron, 2012; Orchowski \& Gidycz, 2012). Approximately half as many men experience such levels of victimization (Turchik, 2012). Roughly two-thirds of victims will disclose to someone, usually a friend, rather than police or campus authorities (Fisher, Daigle, \& Cullen, 2003; Foubert, Langhinrichsen-Rohling, Brasfield, \& Hill, 2010). The limited rate of reporting to authorities is influenced by ideas inherent in rape culture and social norms regarding responsibility for sexual assault and disguises the true extent of the problem (Edwards, Probst, Tansill, Dixon, Bennett, \& Gidycz, 2014). The 2014 National Crime Victimization Survey estimated that fewer than 35\% of U. S. sexual assaults occurring in 2013 were reported to police (Truman \& Langton, 2014), while on college campuses, less than $5 \%$ of assaults are reported to authorities (Rubenfeld, 2014; Sinozich \& Langton, 2014). 
This underreporting is perpetuated by a culture of rape myths that are pervasive across society in general and college campuses, specifically. Rape myths involve false beliefs about sexual assault and commonly deny or minimize impact and promote victim blaming (Powers, Leile, Hagman \& Cohn, 2015). It is the perpetuation of such rape myths that contribute to rape culture, which Burnett et al. (2009) define as "environments that support beliefs conducive to rape and increase risk factors related to sexual violence" (p. 266). Rape culture impacts the way that victims, perpetrators, and bystanders view sexual assault.

\section{Social Norms}

Social norms theory is predicated on the idea that people's behavior and attitudes are influenced by their perception of what others believe. This perception, regardless of its accuracy, often has a powerful influence on behavior. The connection between social norms and attitudes and behaviors regarding sexual assault has been highlighted in recent research (Bosson, Parrot, Swan, Kuchynka, \& Schramm, 2015; Aronowitz, Lambert, \& Davidoff, 2012; Potter \& Stapleton, 2012). The beliefs inherent in rape culture are dangerous, as these "social norms" are predictive of men's comprehension of sexual consent, as well as the actual perpetration of sexual assaults (both single and repeat offenses) (Warren, et al., 2015; Zinzow \& Thompson, 2015). On college campuses, a widespread social norm regarding rape is that the victim is at least partially responsible if they had consumed alcohol or drugs prior to or during the assault (Cowley, 2014). In fact, recent research has found that over $40 \%$ of college students believed that a woman was responsible for being raped if she was intoxicated at the time of the assault (Aronowitz, et al., 2012). This social norm has implications that can perpetuate sexual assault, as it falsely places responsibility on victims and lessens accountability for perpetrators, which can impact the prevalence of sexual assault as well as the likelihood of reporting. Interventions targeting beliefs about rape supportive social norms are recommended as a preventative education strategy to reduce rape supportive behaviors and sexual assault (Bosson. et al., 2015; McMahon, 2015; Potter \& Stapleton, 2012).

\section{Victim Status Awareness}

Victims of nonconsensual sexual contact on college campuses often fail to recognize it as a crime, particularly when they know the perpetrator (Fisher, Daigle \& Cullen, 2003; Jones, Alexander, Wynn, Rossman, \& Dunnuck, 2009). Fisher, Cullen \& Turner (2000) found that $45 \%$ of rapes victims were unsure or unaware that a crime had been committed. Acts of sexual coercion or forcible sex by a partner in an existing relationship are unlikely to be considered sexual assaults, either by the victims or by others (Edwards et al., 2014; Follingstad \& Rogers, 2013), hindering incident reporting. Cleere and Lynne (2013) revealed that fewer than $25 \%$ of women who experienced events that constituted rape actually described their experience as rape, despite over 80\% reporting that they had cried, screamed, pleaded, or physically struggled during the experience. More than half of those surveyed labeled themselves as "not victimized," or else they labeled the event as a "serious miscommunication" (p. 2597). College students may be acculturated to consider sexual assault "not serious enough" to report (Fisher et al., 2003) and may feel campus culture accepts a normalcy for sexual assault perpetration (Burnett et al., 2009), a concept often referred to as rape culture. 


\section{"Unacknowledged Victims"}

Students' reluctance to report unwanted sexual contact by friends or dating partners results in underestimates of the prevalence of campus sexual violence and its impact on victims (Edwards et al., 2014; Sinozich \& Langton, 2014) and creates a population of students that Cleere and Lynn (2013) describe as "unacknowledged victims" (p. 2597). Unacknowledged victims often do not realize that a crime has been committed (Belknap, 2010; Cleere \& Lynn, 2013; Lewis-Arévalo \& Seto, 2014); frequently know their attacker (Edwards et al., 2015); and are unlikely to report the event to police or campus authorities (Orchowski \& Gidycz, 2012; Ullman et al, 2008). Furthermore, by not disclosing their experience, unacknowledged victims potentially miss out on timely support services to aid their recovery and future wellbeing, such as counseling, information about their rights, and medical care, including the collection of a rape kit (Orchowski \& Gidycz, 2012; Sinozich \& Langton, 2014; Wolitzky-Taylor et al., 2011).

\section{Impact of Substance Use on Sexual Assault}

Although sexual assault is assault regardless of substance use, alcohol and other drugs are contributing factors in rape and sexual assault prevalence on college campuses (Edwards et al., 2014; Wilson, 2014). Studies reveal a strong correlation between students' intoxication and incidence of sexual assault (Hines et al., 2012; Krebs, Lindquist, Warner, Fisher, \& Martin, 2009; Pasky McMahon, 2008), with drug or alcohol-facilitated rape more than twice as common (Hines et al., 2012; Krebs et al., 2009). In addition to the increased likelihood of victimization, intoxication reduces the probability that victims hold their attacker responsible, label their experience as a sexual assault (Cleere \& Lynn, 2013; Jones et al., 2009), or report the experience (Edwards et al., 2014; Wolitzky-Taylor et al., 2011).

Victim self-blame. Intoxication at the time of sexual assault contributes to self-blame in many victims (Jones et al., 2009), with 20\% of victims blaming themselves (Edwards et al., 2014). Even for victims who had begged the assailant to stop, assault by an acquaintance resulted in self-blame and minimizing the experience (Edwards et al., 2014). Those who experienced negative judgment were even more likely to blame themselves and increase their alcohol consumption following the assault (Jones et al. 2009; Sigurvinsdottir \& Ullman, 2014). Self-blame impairs psychological healing (Miller, Handley, Markman \& Miller, 2010); and minimizing the assault can contribute to future victimization (Edwards et al., 2014).

\section{Expectation of Disbelief When Reporting}

Fear of being doubted or mistreated by authorities (Orenstein, 2007; Rubenfeld, 2014) and institutional mishandling (Orenstein, 2007; Sable, Danis, Mauzy, \& Gallagher, 2006) are common reasons given for not reporting. Victims of stranger-rape and those who sustained physical injuries reported incidents at a higher rate (Ullman et al., 2008), possibly due to an expectation that their report would be believed and handled appropriately (Follingstad \& Rogers, 2013; Wolitzky-Taylor et al., 2011). Threats from the accused, along with a growing realization of the toll it would take to follow through with an investigation, are precursors to victims recanting their accusations (Adefolalu, 2014; Sinozich \& Langton). Such recantations can perpetuate this culture of disbelief, even though research shows that less than $2 \%$ of reports are filed falsely (Lonsway, 2010). 
DNA evidence can substantiate sexual activity, but not consent. Therefore, absent of physical injury, it is difficult to prove nonconsensual sex. This is especially true for victims in a current or previous relationship with the perpetrator, who may use this history to deny guilt (Belknap, 2010; Menaker, Campbell \& Wells, 2017). It is important to note that regardless of relationship status between victim and perpetrator, assault is assault.

\section{PURPOSE}

As rape culture promotes desensitization to sexual assaults on college campuses (Burnett et al., 2009), understanding the prevalence of victim awareness status can serve as a barometer for college officials to gauge the severity of rape culture on their campuses. This desensitization can also lead to limited reporting, which contributes to the discrepancy in understanding accurate prevalence rates. This discrepancy is further exploited by such research focusing only on those who recognize and identify their own victimization status. The current study categorizes respondents as those who either are, or are not, aware of their own victimization status, and explores group differences in rationale for non-reporting. The purpose of this study is to examine 1) college student awareness of their own sexual assault victimization status, 2) differences between victims who are aware of their victimization status and those who are not (unacknowledged victims) regarding their beliefs as to why most sexual assault victims commonly do not report the incident, 3) and the role of alcohol and other drugs in sexual assault.

\section{METHODS}

\section{Participants and Procedure}

Data for this mixed-methods study came from a universal sample of undergraduate students at two moderately sized institutions of higher education in the mid-Atlantic region, one a public college of 6,135 undergraduate students, and the other a private university in the same county with 4,400 undergraduate students. Students were invited via e-mail to anonymously complete an online survey via Qualtrics survey software, with a lottery incentive for a $\$ 350$ Visa gift card offered for each campus. Due to the sensitive nature of some of the survey questions regarding sexual assault, participants from each campus were provided with the contact information for their perspective campus counseling centers. The Institutional Research Boards from both institutions approved the collection of this data. The sample completing the survey at the public college was 2,034 (33\% response rate), and at the private university was $690(16 \%$ response rate). The samples at each institution are both primarily female (public $=60 \%$, private $=72 \%$ ), Caucasian ( public $=75 \%$, private $=78 \%$ ), and college-aged (public mean age $=20.6$ years, $S D=1.37$, private mean age $=20.3$ years, $S D=3.34)$. 
Table 1: Demographics

\begin{tabular}{|l|l|l|l|l|l|l|l|l|}
\hline & \multicolumn{2}{l}{ Gender } & \multicolumn{3}{l|}{ Academic Year } & & \\
\hline & Male & Female & Freshmen & Sophmores & Juniors & Seniors & $\begin{array}{l}\text { Graduate } \\
\text { Student }\end{array}$ & $\begin{array}{l}\text { Average } \\
\text { Age }\end{array}$ \\
\hline Aware of victim & $.7 \%$ & $2.1 \%$ & $.6 \%$ & $.7 \%$ & $2.8 \%$ & $2.9 \%$ & $1.6 \%$ & 20.8 \\
status & $(\mathrm{n}=6)$ & $(\mathrm{n}=46)$ & $(\mathrm{n}=4)$ & $(\mathrm{n}=5)$ & $(\mathrm{n}=18)$ & $(\mathrm{n}=23)$ & $(\mathrm{n}=4)$ & years \\
\hline Unacknowledged & $4 \%$ & $6.2 \%$ & $4.4 \%$ & $5.6 \%$ & $6.2 \%$ & $6.4 \%$ & $4.3 \%$ & 20 \\
victim status & $(\mathrm{n}=36)$ & $(\mathrm{n}=136)$ & $(\mathrm{n}=30)$ & $(\mathrm{n}=40)$ & $(\mathrm{n}=40)$ & $(\mathrm{n}=50)$ & $(\mathrm{n}=11)$ & years \\
\hline \multirow{2}{*}{ Not a victim } & $96.6 \%$ & $92.7 \%$ & $96.1 \%$ & $95.1 \%$ & $91.9 \%$ & $91.5 \%$ & $95.3 \%$ & 19.9 \\
& $(\mathrm{n}=840)$ & $(\mathrm{n}=1986)$ & $(\mathrm{n}=645)$ & $(\mathrm{n}=666)$ & $(\mathrm{n}=578)$ & $(\mathrm{n}=707)$ & $(\mathrm{n}=241)$ & years \\
\hline
\end{tabular}

\section{Measures}

Alcohol Use Disorder Identifying Test. Alcohol use was assessed using the Alcohol Use Disorder Identifying Test (AUDIT). The AUDIT was created to assess excessive drinking, alcohol dependence, and consequences of harmful drinking (Babor, Higgins-Biddle, Saunders \& Monteiro, 2001), and identify at-risk drinkers who are not seeking treatment (DeMartini \& Carey, 2012). The AUDIT is a 10-item questionnaire and examples of item topics include, "frequency of drinking," "impaired control of drinking," and "black outs" (Babor, Higgins-Biddle, Saunders \& Monteiro, 2001) with possible scores ranging from 0 (minimal drinking or consequences) to 4 (high frequency of drinking or harmful consequences), and total scores ranging from 0 to 40 (McCann, Simpson, Ries, \& Roy-Byrne, 2000). The AUDIT has good internal consistency ( $\alpha$ 0.87) (MCannn et al., 2000) and is a valid instrument to assess alcohol use among college students (Kokotailo Egan, Gangon, Brown, Mundt, \& Fleming, 2004).

Drug Abuse Screening Test. The Drug Abuse Screening Test - Short Form (DAST-10) is a brief self-report instrument used to assess the use of illicit drugs other than alcohol in the last 12 months (McCabe, Boyd, Cranford, Morales, \& Slayden, 2006). Respondents are instructed to answer "yes" or "no" to each item, with example items on the DAST-10 including, "using drugs other than those required for medical reasons" and "feeling bad or guilty about drug use." The DAST-10 has good internal consistency $(a=.86)$, temporal stability (test-retest correlation coefficient $=.71)$, and concurrent validity (correlated .97) (Cocco \& Carey, 1998), and is a valid instrument to assess drug use among college students (McCabe, Boyd, Cranford, Morales \& Slaydon, 2006).

Sexual Assault. Students were asked the following yes/no question about sexual assault victimization: "Have you ever been a victim of sexual violence on your campus?" Students who responded yes to this question were categorized as aware of victim status and asked a yes/no question regarding if they contacted the police about the assault. Those who indicated not contacting the police were asked the following open-ended question: "Can you please describe the reason(s) for your decision to not contact the police?"

Students were also asked the following yes/no question: "In the past year, have you been taken advantage of sexually following your own drinking or drug use?" Students who responded no to being a victim of sexual violence and yes for being taken advantage of sexually after drinking or other drug use were categorized as unacknowledged victims. In order to compare the responses from unacknowledged victims of sexual assault, they were asked the 
following: "Our research shows that women who experience sexual violence on college/university campuses commonly do not report the incident. Why do you think that is?"

\section{Data Analysis}

First, we ran frequencies to determine the number of students who self-identify as victims of sexual assault, whether or not they reported the assault, and if they report being taking advantage of sexually while under the influence of alcohol. A new categorical variable was computed to reflect student awareness of victim status: 1) aware of victim status, 2) unacknowledged victim status, and 3) not a victim. We then explored through Kruskal-Wallis tests whether alcohol use, as measured by AUDIT score, and drug use, as measured by DAST score, are related to awareness of victim status. A Kruskal-Wallis test determines if there are statistically significant differences between two or more groups on continuous dependent variables, in this case testing the comparison of the three victimization status groups on AUDIT and DAST scores.

In addition to quantitative evaluation, we incorporated thematic qualitative data analysis to gain a deeper understanding of participants' perspectives regarding reasons that sexual assault is not reported. Data consisted of the word-for-word responses to the previously identified open-ended survey questions. Responses were separated into categories dependent on victimization status. Researchers became familiar with the data through multiple critical read-throughs, as responses from aware and unacknowledged victims were analyzed independently and then compared. Open coding was utilized throughout analysis to elicit themes, determine patterns, and highlight relationships across the data (Merriam, 2009). Code validation was achieved through review by two additional researchers before themes were finalized. Efforts to increase dependability were employed through the use of an audit trail, where a detailed account was recorded throughout the research inquiry regarding how data was collected and analyzed. Themes from the data, as well as rich, thick description, including specific quotations from participants as applicable, were provided to enhance transferability. This inductive approach enabled us to give voice to victims' viewpoints, as themes emerged from the data based on the words and perceptions of the participants themselves.

\section{RESULTS}

Using the split case function of SPSS 21.0, the assumption of normality was evaluated using histograms and found tenable for both all groups (aware victim, unacknowledged victim, and non-victim). However, the assumption of homogeneity of variances was significant, Levene's Test, $F(2,2154)=10.98, \mathrm{p}=.001$, a violation of this assumption. Given the unequal group sizes and the homogeneity of variances violation, Kruskal-Wallis tests were used to examine the associations between student overall victim awareness status and AUDIT and DAST scores (Pallant, 2007; Tabachinick \& Fidell, 2007). When the overall Kruskal-Wallis test was significant, pairwise comparisons were performed using Mann-Whitney tests.

A Kruskal-Wallis $\mathrm{H}$ test showed that there was a statistically significant difference in AUDIT score between the victim status categories, $\chi^{2}(2)=90.120, p=.001$, with a mean rank AUDIT score of 1333.95 for those aware of their victim status, 1522.87 for unacknowledged victims, and 1040 for those who did not identify as a victim. 
Table 2

Awareness of Victim Status and Alcobol Use

\begin{tabular}{|l|l|l|l|l|}
\hline & M & SD & Observed Range & Possible Range \\
\hline 1. Aware of Victim Status & 7.94 & 5.25 & 23 & 40 \\
\hline 2. Unacknowledged Victim Status & 9.55 & 5.35 & 29 & 40 \\
\hline 3. Non-victims & 5.71 & 4.18 & 30 & 40 \\
\hline
\end{tabular}

To more closely examine the nature of this relationship, we conducted three follow-up Mann-U Whitney tests (Pallant, 2007). After a bonferroni correction, which adjusted the alpha level $(\phi=.017)$ to account for the three follow-up tests, we found that students who reported no victim history had lower AUDIT scores compared to students who were aware of their victim status $(U=34177.5, z=-3.273, p=.001)$. Using Cohen's (1992) parameters, we determined that this was a medium effect size $(d=.47)$. They also reported lower AUDIT scores compared to students who were unacknowledged victims $(U=78750.0, z=-9.031, p=.001)$, a large effect size $(d$ $=.80)$. There was not a significant difference in AUDIT scores between students who were aware of victim status and those who were not $(U=2759, z=-2.154, p=.03)$. There were no significant differences in DAST scores between any victim status categories.

\section{Qualitative Findings}

Qualitative responses were analyzed for two groups of participants who were assaulted: 1) aware of victim status $(n=54), 2)$ unacknowledged victim status $(n=121)$. For the first group, participants who were aware of their sexual assault victimization status, and did not report the assault, answered a prompt asking them to identify their reasons for not reporting. The following three themes emerged from the majority of aware victims: fear and embarrassment, personal connection with the perpetrator, and the presence of alcohol. In comparison, unacknowledged victims also responded to a prompt asking why they believe people do not report sexual assault. The following five themes emerged from their responses: rape culture, societal influence on perception of assault, doubt and uncertainty, involvement of substances, and fear of retaliation. Many of the participants minimized the incident and thought others would as well.

\section{Why Victims Aware of Sexual Assault Did Not Report}

1. Fear and embarrassment. The most common theme aware victims conveyed for not reporting sexual assault centered around fear and embarrassment. Participants reported being afraid of backlash from others, being in the spotlight, and not being believed or supported. Sometimes there was fear of being victimized again. As one participant reported, "I was scared he'd do it again to me if I told (as he threatened)." Coupled with fear was embarrassment, as participants expressed concern about being blamed and the reactions of others if they reported. One senior female shared, "Besides, the guy could always flip the story and make it seem like it was mutual and I 
didn't want to take the risk of being embarrassed." It was clear that a sense of shame or embarrassment acted as an impediment for reporting sexual assault. As one response detailed, "I was ashamed and embarrassed that I was sexually assaulted. I was more worried about getting myself out of the situation. I didn't want anyone to know."

2. Personal connection with attacker. Knowing the attacker was cited as a main reason for not reporting the sexual assault. Multiple participants expressed having some kind of personal relationship with their attacker (e.g. friend, boyfriend, someone they were dating), which factored heavily in their decisions not to report. A common reason given for not reporting was simply, "It was my friend" or "I knew him." Sometimes if the victim had been in a relationship with the person at the time of the attack, it made the situation even more confusing. As one participant noted, "It was with my boyfriend at the time and I didn't know it was sexual violence until after it happened."

A personal connection with the assailant was also related to the victim minimizing the incident of sexual assault. One participant connected these two concepts in her response: "It wasn't a big deal, and it was a friend." Another participant explained that since it was her boyfriend who committed the sexual assault, she believed that "contacting the police was too extreme of a measure." Multiple responses indicated that participants minimized the incident to the point of questioning the legitimacy of what had happened to them. Responses included statements such as: "It didn't seem like a big enough deal;" "his advances weren't too intense so it wasn't a big deal;" and "it was stopped before anything seriously happened." Some participants connected their own discounting of the issue to societal messages regarding sexual assault and who is to blame. As one victim described, "Rape is socially acceptable, (so I) saw (it) as (a) non-issue at the time.”

3. Alcohol. In addition to a personal connection between the perpetrator and victim, the presence of alcohol was mentioned as one of the main reasons for not reporting an assault. Participants seemed to conceptualize the sexual assault differently based on the presence of alcohol. They placed less blame on the assailant and more blame on themselves. As one participant explained, “The guy probably didn't know how drunk I was. I don't want to ruin his entire life." They made statements such as, "I was drunk and felt like it was my fault and no one would believe me." Participants also believed that authorities would not take the situation seriously if alcohol had been involved. Repeatedly, responses including being drunk or being at a party where drinking was taking place were given as reasons for not reporting.

Often there was not one, but multiple reasons that an aware victim chose not to report sexual assault. Increasing the complexity of the decision to report was the intersection of these factors. The multiple layers of concern that ultimately result in victims not reporting are exemplified in the following response:

I was afraid of backlash from the guy/his organization/his friends, I was afraid that no one would believe me. I was ashamed/embarrassed that I was sexually assaulted. I was more worried about getting myself out of the situation. I didn't want anyone to now [sic]. I blamed myself.

\section{Perspectives of Unacknowledged Victims}

When unacknowledged victims (those who identified as being taken advantage of sexually, but did not self-identify as victims of sexual assault) responded to the question of why people do not report, the overarching themes centered around rape culture and involvement of alcohol. Similar to aware victims, embarrassment, fear, and a 
relationship with the attacker were identified as reasons that people do not report sexual assaults. Additionally, several new themes were introduced or emphasized further with these respondents including: societal influence, stigma, and rape culture; lack of awareness related to the meaning of sexual assault or available resources; belief that nothing would be done or people would not believe them; lack of clarity or memory about the incident; and fear specifically related to being attacked again by the perpetrator.

1. Rape culture. In response to the question of why women do not report sexual assault, the most prevalent theme in unacknowledged victims' responses overwhelming centered on themes inherent in rape culture, including societal messages that normalize sexual assault and fear of being doubted. Participants cited "victim blaming" and "slut shaming" and talked about women likely thinking they would be accused of "asking for it" or doing something to prompt the attack. Unacknowledged victims wrote candidly about rape culture. One participant explained:

There is usually a stigma attached to admitting experience of sexual violence. Socially it is very difficult for a woman to escape judgment because we have such a rape culture. Either ineffective punishment or useless "solutions" are provided for the woman who experienced the violence. The female experience with sexual violence is trivialized or girls are blamed for "wanting it."

Respondents described societal messages that are critical of victims' behavior and dress as influential in women's decisions not to report. The stigma and blame often experienced by victims were repeatedly cited as deterrents to reporting. As one participant stated, "There is a stigma in this society where people blame victims, and not the perpetrators." The messages inherent in rape culture were mentioned as reasons that victims feared being blamed by others and also why they blamed themselves.

2. Societal influence on perception of assault. Societal messages were also cited by the majority of participants as a factor in the identification of an incident as sexual assault. The themes that emerged in this area were particularly of note, as these were unacknowledged victims. They stated things such as, "I think cultural attitudes make it difficult when to say you were 'taken advantage of and when you were willing" and "They don't recognize that it is important -- social norms teach them that sexual advancements on women are normal -- nothing important enough to be reported." Unacknowledged victims explained that often women may not even know that what happened to them was sexual assault and may not realize that the definition encompasses more than rape. This is particularly salient on college campuses, as one participant noted, "I think they are hesitant to even recognize an event as sexual violence. They feel as if it a normal occurrence in college and therefore isn't a big deal." Respondents described the confusion that victims might experience when deciding if they should talk about it and from whom they should seek support. This group of respondents noted a lack of awareness around resources and reporting procedures in their answers. They explained that victims might not know where, who, or how to report the incident. One respondent stated her wish that victims "should know there are people out there willing to help."

3. Doubt and uncertainty. Even when victims are aware of reporting options, respondents noted that they may choose not to report because they believe nothing will be done or they will not be believed. One respondent posed the question, "People don't believe them or blame them for it, so why try?" Responses included thoughts that victims would fear not being taken seriously or being accused of "crying wolf." Multiple responses centered on the belief that nothing helpful would result from the reporting process, especially if there was not "hardcore 
evidence." As one unacknowledged victim noted, "There's no incentive for a girl to report the violence, because most of the time not enough action will be taken."

Further complicating the decision to report were reasons centering on victims possibly being unsure or unable to completely remember what happened to them. A respondent reasoned, "The risks seem greater than any reward to a girl in college who may be unsure of what happened." Multiple respondents mentioned that women may be unsure about the details of the incident and therefore would not be able to effectively report it. One of the reasons listed for lack of memory was intoxication from alcohol or drugs. As a respondent described, "Often, if there is alcohol involved, the circumstances of the incident are blurred."

4. Involvement of substances. Similar to the aware victims' responses around the influence of the presence of alcohol on reporting, unacknowledged victims also emphasized the prevalence of alcohol or substances as a deciding factor in reporting. These respondents discussed that the involvement of alcohol might contribute to victims taking more of the responsibility for the assault. They described how women might feel ashamed of being drunk and "putting themselves in an unsafe situation" or embarrassed at "losing control." Other responses explained how authorities might tell victims they were at fault for drinking too much or even drinking at all. Multiple respondents in this group also identified the risk of reporting if the victim was underage drinking or taking illegal drugs with many listing drug or alcohol use as a deterrent for reporting. One unacknowledged victim explained, "Punitive measures for underage alcohol abuse are far too strict in accordance with the goal of wanting victims to come forward."

5. Fear of retaliation. In addition to the fear of getting in trouble because of underage drinking, the fear of retaliation from the perpetrator was emphasized repeatedly amongst unacknowledged victims. Although embarrassment and fear were listed numerous times as reasons for not reporting in both groups, the fear of potentially being attacked again was particularly salient with unacknowledged victims. The reason for this fear was sometimes coupled with the previously mentioned lack of confidence in the outcome of reporting. Responses included, "They are afraid that worse things will happen to them after they report it" and "They may fear that the person who committed the offense will do it again if they tell."

Overall, respondents suggested that there was more risk of harm than help available when reporting. In addition to potential retaliation from the attacker, backlash from friends and family, judgment from others, disbelief or blaming of the victim, and potential social and legal consequences were listed as barriers to reporting. As a participant noted about reporting sexual assault in college, "the risks seem greater than any reward."

\section{DISCUSSION}

Consistent with existing literature, in this study both aware and unacknowledged victims of sexual assault reported higher levels of alcohol use than non-victims. This was a prevalent reason offered from both groups as to why sexual assault is not reported. Researchers report higher levels of alcohol use as both a method of coping with the distress caused by victimization (Stappenbeck, Hassija, Zimmerman \& Kaysen, 2015) and a predictor of sexual assault (White \& Hingson, 2013). Cowley (2013) further expands on this to include how alcohol use, in combination 
with rape myths and gender norms, work together to not only promote, but normalize male dominance and violence against women on college campuses.

While both groups of respondents (aware and unacknowledged victims) described the presence of alcohol and knowing the perpetrator personally as reasons for not reporting, societal influence, stigma, and rape culture were emphasized much more among unacknowledged victims. This suggests that not only do these messages impact the likelihood of reporting, but also seem to influence if an incident is even recognized as an assault by those who are taken advantage of sexually. Rape culture, which contributes to minimizing victimization and promoting self-blame, influences a reporting process that further disempowers victims. Due to mandatory reporting requirements of Title IX officers on college campuses, a student's formal report of sexual assault results in an investigation, leaving the consequences to the perpetrator outside of the control of the victim. In this study, the potential risks and consequences of reporting were a main reason given for not reporting sexual assault.

Media exposure of collegiate sexual assault, and public dialogue that often blames the victim and even glorifies the perpetrator, can lead victims to question the legitimacy of their own victimization and deter reporting. A recent example is the publication of convicted rapist, Brock Turner's competitive swim times in articles about the assault (LaChance, 2016; Preza, 2016). Furthermore, students may question their institution's ability to respond to reports of sexual assault effectively and in a manner that respects and protects victims. This questioning is not without merit, as Smith and Freyd (2013) reported that institutional failure to respond effectively to sexual assault and effectively support victims (a concept they term "institutional betrayal") exacerbates post-traumatic symptomatology and causes additional harm to victims.

It appears as though victims calculate an informal cost-benefit analysis when determining whether or not to report their victimization, with factors including: 1) Will I remember enough facts to report effectively? 2) Will the reporting entity believe me? 3) Will I, or others with me that day get in trouble because I was underage drinking or using drugs when this occurred? 4) Will the outcome of reporting be helpful or safe for me? 5) Will my peers believe and support me? 6) Will there be retaliation from the perpetrator or their friends? and 7) Is any of this really my fault? A combination and intersection of factors appear to influence victims' decisions to report. It is essential that law enforcement officers and faculty and staff in higher education be aware of these reasons, so that prevention and intervention strategies can be employed to effectively address this issue on college campuses.

\section{LIMITATIONS}

As this was a cross-sectional study, design limitations do not allow for the determination of whether reported alcohol and drug use (and differences in use between groups) existed prior to assault, or post-assault as a coping method for victims. Also, as sexual assault was not defined in this survey, the frequency of disclosed victimization is likely under-reported. This is evidenced in the larger number of respondents reporting being taken advantage of sexually when under the influence of alcohol than those reporting being sexually assaulted. There were no questions about being taken advantage of sexually when not under the influence of alcohol, or when under the influence of drug use. Since students appear to define this differently than sexual assault, those individuals would not be captured in this data. 


\section{AREAS FOR FUTURE RESEARCH}

Researchers studying sexual violence should collaborate on the development of a universally accepted definition of sexual assault in order to validly and reliably compare outcomes across studies. Although there has been some movement in this direction (Abbey, 2002), and guidance offered by the Center for Disease Control (Basile, Smith, Breiding, Black \& Mahendra, 2014), there are still a variety of definitions and instruments used in current literature on sexual assault. This diversity in definitions is further complicated by variations from professional fields such as medical, legal, (Teurkheimer, 2015) and research (Bagwell, Messing, Baldwin-White, 2015), which may exacerbate college student uncertainty of what constitutes sexual assault (Ryan, 2011). The US Department of Justice recently hosted an expert panel on how best to measure sexual assault, which is an important next step in leading researchers to a more integrated and universal method of measurement in the future (Kruttschnitt, Kalsbeek \& House, 2013). A multidisciplinary collaboration on a universal definition would also afford sexual violence prevention researchers consistent language to use in helping college students understand the scope of what constitutes sexual violence, potentially reducing the prevalence of unacknowledged victims associated with rape culture. This study showed that certain behaviors, such as being taken advantage of sexually when under the influence of alcohol, are more normalized on college campuses, and therefore future research should focus on deconstructing such perceptions.

\section{CONCLUSION}

There is a clear lack of understanding of what constitutes sexual assault among this college sample, much of which can be attributed to the normalization of assault and rape myths. Having a personal relationship with the perpetrator further impeded the victims' clarity in identifying sexual assault. Regardless of whether a student was aware of their sexual assault victimization status, those who were victimized were significantly more likely to use higher levels of alcohol than nonvictims. There was no difference between victims and nonvictims in regards to drug use severity. The involvement of alcohol or drugs at the time of assault was a primary reason given for not reporting for both aware and unacknowledged victims. The presence of substances resulted in increased fear of consequences and others' perceptions, as well as the victims' own self-blame. Shame and embarrassment were identified as primary reasons for not reporting sexual assault. These feelings were connected to societal messages and college campus norms, which were recognized by students as "victim blaming" and "slut shaming." These elements of rape culture were consistently identified as deterrents to reporting and impediments to victims' own processing of the assault. Overwhelmingly, participants cited the potential consequences as far greater than any potential benefits to reporting sexual assault. Confusion about what constitutes sexual assault and uncertainty of available resources were also recognized as contributing factors in underreporting. 


\section{REFERENCES}

Abbey, A. (2002). Alcohol-related sexual assault: A common problem among college students. Journal of Studies on Alcohol, 14, 118-128. https://doi.org/10.15288/jsas.2002.s14.118

Aronowitz, T., Lambert, C. A., \& Davidoff, S. (2012). The role of rape myth acceptance in the social norms regarding sexual behavior among college students. Journal of Community Health Nursing, 29(3), 173-182. https://doi.org/10.1080/07370016.2012.697852

Babor, T., Higgins-Biddle, J., Saunders, J. \& Monteiro, M. (2001). Alcohol Use Disorders Identification Test. World Health Organization: Department of Mental Health and Substance Dependence. CH-1211 Geneva 27, Switzerland

Bagwell-Gray, M. E., Messing, J. T., \& Baldwin-White, A. (2015). Intimate partner sexual violence: A review of terms, definitions, and prevalence. Trauma, Violence, \& Abuse, 16(3), 316-335.

https://doi.org/10.1177/1524838014557290

Basile, K.C., Smith, S.G., Breiding, M.J., Black, M.C. \& Mahendra, R.R. (2014). Sexual Violence Surveillance: Uniform Definitions and Recommended Data Elements, Version 2.0. Atlanta (GA): National Center for Injury Prevention and Control, Centers for Disease Control and Prevention.

Belknap, J. (2010). Rape: Too hard to report and too easy to discredit victims. Violence Against Women, 16(12), 13351344. https://doi.org/10.1177/1077801210387749

Bosson, J. K., Parrott, D. J., Swan, S. C., Kuchynka, S. L., \& Schramm, A. T. (2015). A dangerous boomerang: Injunctive norms, hostile sexist attitudes, and male-to-female sexual aggression. Aggressive Behavior, 41(6), 580-593. https://doi.org/10.1002/ab.21597

Burnett, A., Mattern, J., Herakova, L., Kahl, D., Tobola, C. \& Bornsen, S. (2009). Communicating/muting date rape: A co-cultural theoretical analysis of communication factors related to rape culture on a college campus. Journal of Applied Communication Research, 37(4), 465-485. https://doi.org/10.1080/00909880903233150

Cleere, C., \& Lynn, S. J. (2013). Acknowledged versus unacknowledged sexual assault among college women. Journal of Interpersonal Violence, 28(12), 2593-2611. https://doi.org/10.1177/0886260513479033

Cocco, K. \& Carey, K. (1998). Psychometric properties of the Drug Abuse Screening Test in psychiatric outpatients. Psychological Assessment, 10(4), 408-414. https://doi.org/10.1037/1040-3590.10.4.408

Cowley, A. (2014). "'Let's get drunk and have sex': The complex relationship of alcohol, gender, and sexual victimization.” Journal of Interpersonal Violence, 29(7), 1258-1278. https://doi.org/10.1177/0886260513506289

DeMartini, K. \& Carey, K. (2012). Optimizing the use of the AUDIT for alcohol screening in college students. Psychological Assessment, 24, 954-963. https://doi.org/10.1037/a0028519

Edwards, K. M., Probst, D. R., Tansill, E. C., Dixon, K. J., Bennett, S., \& Gidycz, C. A. (2014). In their own words: A content-analytic study of college women's resistance to sexual assault. Journal of Interpersonal Violence, 29(14), 2527-2547. https://doi.org/10.1177/0886260513520470

Edwards, K. M., Sylaska, K. M., Barry, J. E., Moynihan, M. M., Cohn, E. S., Walsh, W. A., \& Ward, S. K. (2015). Physical dating violence, sexual violence, and unwanted pursuit victimization: A comparison of incidence rates among sexual-minority and heterosexual college students. Journal of Interpersonal Violence, 30(4), 580-600. https://doi.org/10.1177/0886260514535260 
Fisher, B. S., Cullen, F. T., \& Turner, M. G. (2000). The sexual victimization of college women. (Research Report No. NCJ 182369). Washington, DC: Bureau of Justice Statistics, Department of Justice.

Fisher, B. S., Daigle, L. E., \& Cullen, F. T. (2003). Reporting sexual victimization to the police and others: Results from a national-level study of college women. Criminal Justice \& Behavior, 30(1), 6-38. https://doi.org/10.1177/0093854802239161

Follingstad, D., \& Rogers, M. (2013). Validity concerns in the measurement of women's and men's report of intimate partner violence. Sex Roles, 69(3-4), 149-167. https://doi.org/10.1007/s11199-013-0264-5

Foubert, J. D., Langhinrichsen-Rohling, J., Brasfield, H., \& Hill, B. (2010). Effects of a rape awareness program on college women: Increasing bystander efficacy and willingness to intervene. Journal of Community Psychology, 38, 813-827. https://doi.org/10.1002/jcop.20397

Hines, D. A., Armstrong, J. L., Reed, K. P., \& Cameron, A. Y. (2012). Gender differences in sexual assault victimization among college students. Violence \& Victims, 27(6), 922-940. https://doi.org/10.1891/08866708.27.6.922

Jones, J. S., Alexander, C., Wynn, B. N., Rossman, L., \& Dunnuck, C. (2009). Why women don't report sexual assault to the police: The influence of psychosocial variables and traumatic injury. The Journal of Emergency Medicine, 36(4), 417-424. https:/ / doi.org/10.1016/j.jemermed.2007.10.077

Kokotailo, P., Egan, J., Gangnon, R., Brown, D., Mundt, M. \& Fleming, M. (2004). Validity of the alcohol use disorders identification test in college students. Alcoholism: Clinical and Experimental Research, 28, 914-920. https://doi.org/10.1097/01.ALC.0000128239.87611.F5

Krebs, C. P., Lindquist, C. H., Warner, T. D., Fisher, B. S., \& Martin, S. L. (2009). College women's experiences with physically forced, alcohol- or other drug-enabled, and drug-facilitated sexual assault before and since entering college. Journal of American College Health, 57(6), 639-649. https://doi.org/10.3200/JACH.57.6.639649

Kruttschnitt, C., Kalsbeek, W. \& House, C. (2013). Estimating the Incidence of Rape and Sexual Assault. Panel on Measuring Rape and Sexual Assault in Bureau of Justice Statistics Household Surveys; Committee on National Statistics; Division on Behavioral and Social Sciences and Education; National Research Council. The National Academies Press, Washington D.C.

LaChance, N. (2016). Media continues to refer to Brock Turner as a "Standford Swimmer" rather than a rapist. The Intercept. Retrieved from https://theintercept.com/2016/09/02/media-continues-to-refer-to-brock-turneras-a-stanford-swimmer-rather-than-a-rapist/

Lewis-Arévalo, C., \& Seto, A. (2014). Reducing campus sexual assaults through bystander intervention programs: How counselors can help. Journal of Counselor Leadership and Advocacy, 1(2), 128-139. https://doi.org/10.1080/2326716X.2014.902760

Lonsway, K. A. (2010). Trying to move the elephant in the living room: Responding to the challenge of false rape reports. Violence Against Women, 16(12), 1356-1371. https://doi.org/10.1177/1077801210387750

McCabe, S., Boyd, C., Cranford, J., Morales, M. \& Slayden, J. (2006). A modified version of the Drug Abuse Screening Test among undergraduate students. Journal of Substance Abuse Treatment, 31(3), 297-303. https://doi.org/10.1016/j.jsat.2006.04.010 
McMahon, S. (2015). Call for research on bystander intervention to prevent sexual violence: The role of campus environments. American Journal of Community Psychology, 55(3/4), 472-489. https:/ /doi.org/10.1007/s10464015-9724-0

Menaker, T. A., Campbell, B. A., \& Wells, W. (2017). The use of forensic evidence in sexual assault investigations: Perceptions of sex crimes investigators. Violence Against Women, 23(4), 399-425. https://doi.org/10.1177/1077801216641519

Merriam, S.B. (2009). Qualitative research: A guide to design and implementation. San Francisco, CA: Jossey-Bass.

Miller, A., Handley, I., Markman, K. \& Miller, J. (2010). Deconstructing self-blame following sexual assault: The critical roles of cognitive content and process. Violence Against Women, 16(10), 1120-1137. https://doi.org/10.1177/1077801210382874

Orchowski, L. M., \& Gidycz, C. A. (2012). To whom do college women confide following sexual assault? A prospective study of predictors of sexual assault disclosure and social reactions. Violence Against Women, 18(3), 264-288. https://doi.org/10.1177/1077801212442917

Orenstein, A. (2007). Special issues raised by rape trials. Fordham Law Review, 76(3), 1585-1608.

Pallant, J. (2007). SPSS survival manual (3 ${ }^{\text {rd }}$ ed.). New York: McGraw Hill.

Pasky McMahon, P. (2008). Sexual violence on the college campus: A template for compliance with federal policy. Journal of American College Health, 57(3), 361-366. https://doi.org/10.3200/JACH.57.3.361-366

Potter, S. J., \& Stapleton, J. G. (2012). Translating sexual assault prevention from a college campus to a United States Military installation: Piloting the Know-Your-Power Bystander Social Marketing Campaign. Journal of Interpersonal Violence, 27(11), 1593-1621. https://doi.org/10.1177/0886260511425795

Powers, R. A., Leili, J., Hagman, B., \& Cohn, A. (2015). The Impact of College Education on Rape Myth Acceptance, Alcohol Expectancies, and Bystander Attitudes. Deviant Behavior, 36(12), 956-973. https://doi.org/10.1080/01639625.2014.982747

Preza, E. (2016). Washington Post offers 'rape apologist' article about Brock Turner- Gets righteously slammed. Alternet. Retrieved from http://www.alternet.org/media/twitter-excoriates-washington-post-offering-rapeapologist-article-brock-turners-conviction

Rubenfeld, J. (2014, Nov 16). Mishandling rape. New York Times, pp. SR.1.

Ryan, K. M. (2011). The relationship between rape myths and sexual scripts: The social construction of rape. Sex Roles, 65(11-12), 774-782. https://doi.org/10.1007/s11199-011-0033-2

Sable, M. R., Danis, F., Mauzy, D. L., \& Gallagher, S. K. (2006). Barriers to reporting sexual assault for women and men: Perspectives of college students. Journal of American College Health, 55(3), 157-162. https://doi.org/10.3200/JACH.55.3.157-162

Sigurvinsdottir, R. \& Ullman, S. (2014). Social reaction, self-blame and problem drinking in adult sexual assault survivors. Psychology of Violence, 5(2), 192-198. https://doi.org/10.1037/a0036316

Sinozich, S., \& Langton, L. (2014). Rape and Sexual Assault Among College-Age Females, 1995-2013. (No. NCJ 248471). Bureau of Justice Statistics. 
Smith, C. \& Freyd, J. (2013). "Dangerous safe havens: Institutional betrayal exacerbates sexual trauma.” Journal of Traumatic Stress, 26, 119-124. https://doi.org/10.1002/jts.21778

Stappenbeck, C., Hassija, C., Zimmerman, L. \& Kaysen, D. (2015). Sexual assault related distress and drinking: The influence of daily reports of social support and coping control. Addictive Behaviors, 42, 108-113. https://doi.org/10.1016/j.addbeh.2014.11.013

Truman, J. L., \& Langton, L. (2014). Criminal Victimization, 2013 (revised). (No. NCJ 247648). Bureau of Justice Statistics.

Tuerkheimer, D. (2015). Rape on and off campus. Emory Law Journal, 65(1), 1-45.

Turchik, J. A. (2012). Sexual victimization among male college students: Assault severity, sexual functioning, and health risk behaviors. Psychology of Men \& Masculinity, 13(3), 243-255. https://doi.org/10.1037/a0024605

Ullman, S. E., Starzynski, L. L., Long, S. M., Mason, G. E., \& Long, L. M. (2008). Exploring the relationships of women's sexual assault disclosure, social reactions and problem drinking. Journal of Interpersonal Violence, 23, 1235-1257. https://doi.org/10.1177/0886260508314298

Warren, P., Swan, S., \& Allen, C. T. (2015). Comprehension of sexual consent as a key factor in the perpetration of sexual aggression among college men. Journal of Aggression, Maltreatment \& Trauma, 24(8), 897-913. https://doi.org/10.1080/10926771.2015.1070232

White, A. \& Hingson, R. (2013). The burden of alcohol use: Excessive alcohol consumption and related consequences among college students. Alcohol Research: Current Reviews, 35(2), 201-218.

Wilson, R. (2014). Why colleges don't talk about alcohol's role in sex assaults. Chronicle of Higher Education, 61(2), A4-A4.

Wolitzky-Taylor, K., Resnick, H. S., Amstadter, A. B., McCauley, J. L., Ruggiero, K. J., \& Kilpatrick, D. G. (2011). Reporting rape in a national sample of college women. Journal of American College Health, 59(7), 582-587. https://doi.org/10.1080/07448481.2010.515634

Zinzow, H., \& Thompson, M. (2015). A Longitudinal study of risk factors for repeated sexual coercion and assault in U.S. college men. Archives of Sexual Behavior, 44(1), 213-222. https://doi.org/10.1007/s10508-013-0243-5

Address author correspondence to:

Sandy Gibson, PhD, LCSW

Associate Professor

Clinical Coordinator

Department of Counselor Education

PO Box 7718 Ewing, NJ 08628-0718

gibsonc@tcnj.edu 